\title{
¿POR QUÉ LA MEDICINA LE INTERESA AL ESCEPTICISMO? UNA PROPUESTA
}

\section{Alejandro G. Miroli*}

Resumen: Este trabajo estudia la relación entre escepticismo pirrónico y medicina en el escenario contemporáneo a partir de una caracterización del escepticismo contemporáneo y de las escuelas médicas del presente. Para ello se propone (i) que hay un tipo de saber que corresponde a la noción de una experiencia purificada por la epokbé y es el conocimiento narrativo, (ii) que la Medicina Basada en Narraciones (MBN) es la escuela médica que se pueda vincular con el proyecto neopirrónico y (iii) que $\mathrm{MBN}$ es un caso testigo para analizar el rol criteriológico del conocimiento narrativo.

Palabras clave: Conocimiento narrativo, neopirronismo, creencia asertiva, creencias constatativas, Modelo Médico.

\begin{abstract}
This paper studies the relationship between Pyrrhonian skepticism and medicine in the contemporary scenario and tries to offer a characterization of contemporary skepticism and of present day medical schools. We propose (i) that there is a kind of knowledge that corresponds to the notion of an experience purified by epokbé which is the narrative knowledge, (ii) that Narrative Based Medicine (MBN) is the medical school that can be linked to the neopyrrhonian project and (iii) that $\mathrm{MBN}$ is a leading case for analyzing the criteriological role of narrative knowledge.
\end{abstract}

Key words: Narrative knowledge, assertive belief, Neo-pyrrhonism, constative beliefs, Medical Model.

* Licenciado en Filosofía, profesor de las asignaturas Metodología de las Ciencias Sociales (UBA/CBC), Filosofía de la Ciencia y Filosofía de la Tecnología (USAL) y Filosofía de la Historia (Instituto "Alfredo L. Palacios"). Dirección de correo electrónico: alexmir@arnet.com.ar. 


\section{El encuadre histórico ${ }^{1}$.}

Las relaciones entre escepticismo y medicina se remontan a la presentación que hiciera Sexto Empírico del escepticismo pirrónico, donde explora las relaciones del escepticismo pirrónico con las escuelas médicas Empírica y Metódica (véase, por ejemplo, Hipotiposis pirrónicas, I, 236-241) ${ }^{2}$, y su exposición es tópica: los escépticos pirrónicos se diferenciaban de la Escuela Médica Empírica porque ésta pretendía tener conocimiento sobre materias inaprehensibles; se asemejaban, en cambio, a la Escuela Médica Metódica (cuya fundación se atribuye a Asclepíades de Bitinia o a su discípulo Temisón de Laodicea) porque ambos callaban sobre dichas materias.

En efecto, para Sexto Empírico, el médico metódico se asemejaba al pirrónico, pues sólo éste, a diferencia de otras sectas médicas, parece no precipitarse en la consideración de lo oscuro arriesgando afirmar que sea comprensible o incomprensible, sino que, siguiendo las apariencias, acepta de éstas lo que parece conveniente, siguiendo el modelo de los escépticos" (HP, I, 237). Y así como el criterio pirrónico, el criterio de los médicos metódicos "es cuádruple, consistiendo una parte en la guía de la naturaleza, otra en la compulsión de las sensaciones, otra en la tradición de leyes y costumbres y otra en la instrucción de las artes" (HP, I, 238).

Esta relación entre escepticismo y medicina también aparece en la Modernidad: Francisco Sanches, médico de formación a quien Richard

\footnotetext{
${ }^{1}$ En este trabajo emplearemos las expresiones agente terapéutico y sujeto que padece, en tanto las nociones médico y enfermedad son normativas, y dependen de la división disciplinar de las ciencias de la salud: médico designa una profesión definida par leyes de ejercicio profesional; por otro lado enfermedad no es una clase natural sino un tipo institucional, que es lógicamente independiente de los padecimientos subjetivos.

2 Seguimos la edición de Rafael Sartorio Maulini: Sexto Empírico, Hipotiposis pirrónicas, Barcelona, Akal, 2006. Nos referiremos a la misma mediante las siglas HP y, siguiendo los criterios de cita de las obras clásicas, se citará por libro en numeración romana y párrafo en numeración arábiga.
} 
Popkin $^{3}$ presenta como un autor que desarrolla un itinerario propio que no es tributario de la lectura de las fuentes clásicas y que inaugura las puertas de la subjetividad moderna en su clásico Quod nibil scitur. En esa vena se encuentran también Martín Martínez con su Medicina Scéptica y Fr. Benito Jerónimo Feijoo con su Apología del Escepticismo Médico.

En la actualidad, el sintagma "escepticismo médico" tiene un significado completamente diferente al que tenía en los autores clásicos o modernos. En efecto, las declaraciones actuales de escepticismo en materia de medicina designan a quienes se dedican a la revisión crítica de las llamadas Medicinas Alternativas y Complementarias, con lo cual el llamado escepticismo médico configura un caso de lo que hemos llamado en otro lugar escepticismo cientifico, el que sólo tiene un parecido circunstancial con el escepticismo clásico ${ }^{4}$.

\section{El encuadre contemporáneo. El pirronismo actual}

Más allá de esa variedad particular de escepticismo que sea el llamado escepticismo médico, cabe la pregunta: ¿es posible recuperar la relación entre escepticismo y medicina, en el sentido que la comprensión de la medicina actual permita entender algunos rasgos de la investigación escéptica o zétesis? Esto supone examinar los dos términos de esta relación y determinar que se entenderá por escepticismo y medicina en el presente.

${ }^{3}$ Popkin, Richard, The History of Scepticism From Savonarola to Bayle, Nueva York, Oxford University Press, 2003, pp. 39-43.

${ }^{4}$ El escepticismo científico involucra entre otros la obra de Paul Kurtz, Michael Shremer, Carl Sagan, Martin Gardner, Milton A. Rothman, Victor Stenger, cf. Miroli, A. (2007) "Un examen de la relación entre escepticismo y epistemología: el caso del llamado escepticismo científico", en P. Lorenzano y H. Miguel (eds.), Filosofía e Historia de la Ciencia en el Cono Sur, Buenos Aires, Editora CCC Educando, 2007, pp. 353-363. 
Para determinar el primer término de esa relación debemos partir de alguna posición contemporánea, y en ese sentido pocos filósofos han desarrollado una indagación escéptica pirrónica genuina y sistemática como Oswaldo Porchat Pereira. Señala nuestro autor que en la "tradición escéptica, uno de los motivos para la suspensión del juicio era la diaphonía que ocurría cuando [citando a Sexto Empírico: HP, I, 65-66] descubrimos que se da una irresoluble disputa, tanto entre la gente ordinaria como entre los filósofos, acerca del objeto propuesto; por lo que, al no poder elegir o rechazar nada, concluimos en la suspensión del juicio". Porchat Pereira hace suyo ese diagnóstico y expone una concepción de la filosofía que se puede llamar la "concepción del museo filosófico", que consiste en "una pluralidad de sistemas, concepciones y actitudes que se suceden en el tiempo histórico sin ninguna unidad ni método" y que se vinculan polémicamente entre sí. "La polémica incesante entre las doctrinas, la descalificación permanente de las posiciones rivales, la excomunión recíproca se repiten con monotonía a lo largo de la historia de la filosofía", agrega Porchat ${ }^{5}$. Esta situación se hace más complicada porque pertenece "a cada filosofía el deber de imponerse como la única y verdadera filosofía"'.

Así, cada pieza de ese museo es un sistema con pretensiones de totalidad que surgen de los principios que lo articulan. En la concepción del museo filosófico, la diaphonia no es una mera proliferación, sino una proliferación dilemática, en la que cada elemento supone la exclusión y refutación del otro. "Cada filosofía dogmática engendra sus tesis en un movimiento del discurso que procede por argumentación"; tal discurso tiene una pretensión universal estricta, ya que "pertenece a la esencia de la filosofía dogmática el proponerse como capaz de persuadir y convencer a todo hombre razonable que sea suficientemente capaz de acompañar su proceso argumentativo"7. Estas filosofías dogmáticas querrán persuadir al "auditorio formado por la comunidad racional a la que el filósofo se dirige

${ }^{5}$ Porchat Pereira, O.,Vida Comun e Ceticismo, San Pablo, Editora Brasiliense, 1993, p. 168.

${ }^{6}$ Ibíd., p. 28.

${ }^{7}$ Ibíd., pp. 215-6. 
siempre"8. De ese modo, el museo filosófico exhibe un movimiento de pro-argumentos y contra-argumentos que exponen la pericia de los profesantes de cada escuela para encontrar problemas lógicos o metodológicos en las afirmaciones de otras escuelas. Cualquier intento de salir de esa trampa, por otra parte, nos lleva también a ella: el conflicto no se puede resolver desde dentro de uno de los sistemas o doctrinas, lo que nos obligaría a permanecer fuera del universo de discurso de las restantes, ni desde el mundo de la experiencia común, ya que cada doctrina ha tematizado lo común de una manera distinta a las demás, ni apelando a las ciencias, porque no hay un único modo de vinculación de conocimiento científico y doctrina filosóficas, ni, finalmente, desde una explicación pretendidamente científica del origen de tales doctrinas, porque la génesis no ofrece una explicación de las pretensiones de validez".

La diaphonía promueve la epokbé y el silencio sobre materias que exigen creencias asertivas. Ahora bien ¿qué queda luego de la epokbe? Porchat rechaza de plano que después de la epokbé quede un supuesto saber común; él mismo reconoce haber apelado a tal saber mundano en sus primeros trabajos, pero luego rechazó tal apelación, porque el hombre común también es un dogmático, y la epokbé no sólo alcanza a la filosofía y ciencia académicas, sino que llegará a todas las creencias mundanas dogmáticas y a las certezas subjetivas fundadas en la seguridad psicológica o en la vivacidad que tiene la mayoría de nuestras creencias asertivas ${ }^{10}$.

Pero, ¿me quedo en la mera epokhée Si la aceptación de las pretensiones dogmáticas nos condenaba a una constante zozobra intelectual, la epokbé ilimitada parecería condenarnos "a la inacción o la muerte" y es claro que, si éste fuera el resultado de la epokbé, la relevancia del neopirronismo para los filósofos sería nula. Sin embargo, Porchat propone una interpretación de la epokbé que no termina en una aniquilación de toda posibilidad reflexiva o vital, sino que intenta

8 Porchat Pereira, O., "O Ceticismo Pirrónico e os Problemas Filosoficos", Cadernos de História e Filosofia da Ciênca, serie 3, vol. 6, 1996, p. 100.

9 Porchat Pereira, O., Vida Comun e Ceticismo, pp. 11-15.

${ }^{10}$ Ibíd, p. 173. 
caracterizar a partir de ella una realidad y un lenguaje putativos que le permita deslindar un ámbito de la experiencia que sea inmune al tropo escéptico de la diaphonía. Sigamos a Porchat Pereira en su exploración de una situación típica: "imaginemos algunos filósofos alegremente reunidos a tomar cerveza en torno a la mesa de un bar (...) Sus grandes divergencias filosóficas obviamente no les impiden entenderse entre sí y con el camarero sobre un gran número de cosas, de describir de modo idéntico objetos y eventos familiares a su derredor, como lo hacen los hombres en la plaza o en el mercado"11. Si uno de estos filósofos intentara irse sin pagar aduciendo que como es solipsista el mundo depende de sus percepciones y deseos, fácilmente podemos imaginar adónde iría a parar. Más allá de sus diferencias doctrinarias, todos ellos comparten una serie de "fenómenos comunes", y la marca de esa comunidad es "lo que a todos se impone innegablemente (...) lo que se nos aparece se nos impone con necesidad, a ello no podemos sino asentir, en su aparecer es absolutamente incuestionable (...) no podrá ser objeto de duda"12. Esto permite entender que la epokhé deja en pie un "asentimiento compulsivo a lo que se nos aparece, a lo que se nos impone innegablemente, -lo que no ES otra cosa sino nuestro mismo reconocimiento del fenómeno- (...) los escépticos creemos en los fenómenos" y a lo que corresponden ciertas certezas concomitantes. "[E]star ciertos de algo [no es] atribuir un estatuto epistemológico a nuestra certeza, un estatuto ontológico a su objeto [sino] tomar solamente parte del juego de vida cotidiana en el que estamos comprometidos"13. Sexto Empírico enfatizaba este punto mediante diversas expresiones ("sin mediar nuestra voluntad", "involuntaria", "incuestionable", "se imponen", "independientemente de la voluntad") y el mismo permite dar una cierta caracterización general de lo que aparece: (DA) lo-que-aparece $=10$ inescapable $/$ irrenunciable $/$ involuntario $=$ contenidos de experiencia que una comunidad de sujetos puede reconocer como comunes = creencias no asertivas/dogmáticas $\approx$ experiencia de filósofos ante una mesa de café.

11 Ibíd., p. 181-2.
12 Ibíd., pp. 182, 176-177.
${ }^{13}$ Ibíd., pp. 194-195. 
De acuerdo con esta definición, no habría ninguna continuidad entre el antiguo modo de hablar de creencias asertivas y el modo de hablar purificado por la epokhé; éste, por otra parte, se podrá reconocer como un modo de hablar genuino ya que la epokbé no "afectó (...) el contenido inmediato de mi experiencia cotidiana (...) todos los hombres tienen experiencias como ésa y no las niegan ni las pueden denegar" 14 .

De esta manera, Porchat Pereira opone a la pars destruendum de la zétesis pirrónica, una pars contruendum que sería su elaboración personal y que supone reconocer que hay "una infinita gama de problemas filosóficos que se sitúan compresiblemente fuera del alcance de la suspensión pirrónica del juicio"15. La exploración del ámbito filosófico de una experiencia purificada que sobrevive a la epokbé supone un proceso de creciente clarificación a partir de la propia caracterización de la filosofía: ésta es vista como una actividad que produce filosofemas, que son soluciones totales o parciales a problemas filosóficos con pretensiones de aceptabilidad por una comunidad de sujetos razonadores que reconoce su legitimidad.

\section{II.2 Rasgos del pirronismo actual. La experiencia purificada.}

La exposición anterior presenta un cuadro de clara estirpe pirrónica en el escenario de la filosofía contemporánea, sin pretender que sea una interpretación verdadera de la obra de Porchat Pereira. Dado ese cuadro, podemos atisbar dos rasgos básicos. El primero de ellos es la experiencia purificada; en dicho ámbito, el vocabulario epistémico que se emplee para caracterizar y evaluar los estados de conocimiento propios - evidencia, certeza, verdad, coherencia, grado de aceptabilidad, verosimilitud, validez cognitiva, apoyo empírico, justificación, grado de confirmación, etc.- muta su significado en forma completa y pierde los

\footnotetext{
14 Ibíd., p. 176.

15 Porchat Pereira, O., "O Ceticismo Pirrónico e os problemas filosoficos", p. 136.
} 
significados que tenía el ámbito de la experiencia dogmática. De ese modo habría un abismo entre la teoría de los saberes y criterios de la experiencia dogmática y lo que podríamos llamar por mera analogía la doctrina ${ }^{16}$ de los saberes y criterios de la experiencia purificada. Esta "doctrina del conocimiento" operará con informes y relatos que se constaten sin dogmatizar ${ }^{17}$ y los someterá a una inspección criteriológica ${ }^{18}$, sin que ello provea de fuerza asertiva a esas constataciones. $Y$ en este ámbito hay numerosos problemas que se pueden expresar con el lenguaje constatativo: hacer discriminaciones más afinadas, obtener menores tiempos de reacción en nuestras acciones, lograr efectos más duraderos, reconocer lazos temáticos entre lo-que-aparece como recuerdo y lo-que-

${ }^{16}$ A fin de establecer una diferencia técnica, usamos la palabra teoría para las pretensiones de una filosofía dogmática y la palabra doctrina para el conjunto de informes o relatos sobre los usos criteriológicos que haga un pirrónico.

${ }_{17}$ Dado que el lenguaje que emplea el escéptico pirrónico es una constatación de lo que aparece sin juzgar nada por sí, podemos introducir la noción de creencias constatativas como aquellos estados doxásticos que acompañan a las constataciones de aquello que aparece.

18 Desde su formulación originaria el escepticismo pirrónico reconoció la presencia de criterios: así, por ejemplo, Pirrón aseguraba que no seguía nada dogmático sino que se dejaba llevar por lo que aparece (Diógenes Laercio, Vidas de los filósofos ilustres, IX, 106) ya que "es necesario que el filósofo aporético, tenga un criterio de elección y de refutación, y éste es lo-que-aparece (...) como testimonia Timón" (Sexto Empírico, Adversus Matbematicos, VII, 30). En la exposición que hace Sexto Empírico se reconocía que "no negamos lo que de acuerdo con la sensación pasiva nos conduce involuntariamente al asentimiento, y eso son las apariencias y que "investigamos no sobre la apariencia, sino lo que se afirma acerca de la apariencia" (HP, 19-20). De ese modo "dando crédito a las apariencias según la observación vital, vivimos sin dogmatizar ya que no podemos quedar completamente inactivos" (HP, I.23). Dicho criterio escéptico tenía cuatro formas: "En virtud de la guía de la naturaleza somos naturalmente capaces de sensación y conocimiento; por la compulsión de las sensaciones, el hambre nos dirige a la comida y la sed a la bebida; por la tradición de las leyes y costumbres, consideramos la piedad en la vida como buena y la impiedad como mala; finalmente, gracias a la instrucción de las artes no somos incompetentes en aquellas artes que cultivamos" (HP I. 26-7). 
aparece en tiempo presente, etc. Esta capacidad de enriquecer el ámbito de una experiencia purificada y de distinguir celosamente entre lo-queaparece y lo que se propone asertivamente, no sólo se aplica a la experiencia de las cosas que nos rodean y son comunes a otros agentes, sino a nuestra propia experiencia de tener creencias.

\section{II.3 Rasgos del pirronismo actual. Los conglomerados de tekhnai.}

El otro rasgo que podemos señalar es la presencia de lo que podemos llamar conglomerados técnicos o de tékbnai. Señala Porchat que los pirrónicos quedan "viviendo adogmáticamente la vida común y compartiéndola como los otros seres humanos, utilizando las enseñanzas de aquellas disciplinas (tékehnal) (...) que organizan y sistematizan los fenómenos para el beneficio de todos" 19 . Estas tékhnai pueden reconocerse desde aquelloque-aparece como siendo común a todos los que comparten una situación, por ejemplo, cada uno de los comensales de la mesa de filósofos: las botellas de soda, los platos y las tazas, el recipiente de azúcar, el servilletero serían lo-que-aparece-en-común a cada uno, ya que detrás de cada elemento que aparece habrá una tékhne que se encadenará en cosas que también aparecerán como partes, como auxiliares, como resultados. Así:

(i)

en la mesa del café nos aparece madera cepillada y espigada como experiencia organizada que nos remite a las labores de carpinteros y los madereros,

en el azucarero que acompaña las bebidas nos aparece el azúcar como experiencia organizada que nos remite a los cañeros y las actividades de refinación,

19 Porchat Pereira, O., "O Ceticismo Pirrónico e os problemas filosoficos", p. 137. Puede compararse con la siguiente observación de Sexto Empírico "basta, creo, vivir siguiendo la experiencia y sin dogmatizar, según los comportamiento y las nociones comunes, suspendiendo el juicio respecto de las afirmaciones de la sutileza dogmática, por completo carentes de utilidad para la vida" (HP II, 246). 
(iii)

el vidrio de los vasos como experiencia organizada nos remite a las fábricas de vidrio y a los preparadores de arenas,

(iv)

el café molido como experiencia organizada nos remite a los cultivadores y secadores del grano de café.

Cada situación-que-aparece en solitario o en común involucrará, pues, un conglomerado de cosas-que-aparecen organizado e identificable con otros conglomerados; de ese modo, cada cosa-que-aparece se podrá considerar como un foco de una red de remisiones posibilitadas por las correspondientes tékhnai que estén involucradas, y cada tékhne a su vez podrá remitir a nuevas tékhnai.

Este proceso que descubre una red de tékhnai se desenvuelve "en la actualización progresiva de la investigación del mundo fenoménico, en el enriquecimiento y perfeccionamiento de la imagen común del mundo, de ese mundo que de modo insistente le aparece como susceptible de una descripción consensual. Sobre ese prisma se puede decir que se delinea algo como (...) acuerdo intersubjetivo"20.

El acuerdo intersubjetivo no será ni una ficción filosófica ni un recurso contrafáctico, ni una suerte de acuerdo voluntario; por lo contrario, son los conglomerados de tékhnai que se remiten unos a otros lo que permite que cada agente pueda recorrer los lazos que los unen, tomando algún objeto o práctica cualquiera y llegar hasta las técnicas más alejadas: es esta estructura lo que ordena y dispone el acuerdo intersubjetivo y la vida común en la experiencia purificada. Así la discriminación entre creencias constatativas y creencias asertivas involucra la propia ubicación de este agente en una retícula de conglomerados de tékhnai, no solo como contenidos psicológicos sino como capacidades para obrar.

20 Porchat Pereira, O., "Verdade, Realismo, Ceticismo", Discurso, 25, 1995, pp 4650. También Porchat Pereira, O., "O Ceticismo Pirrónico e os Problemas Filosoficos", p. 138. 


\section{La doctrina del conocimiento constatativo-criteriológico.}

La tradición más influyente en la epistemología occidental ha empleado la noción de representación como noción básica para elucidar el conocimiento y la creencia, al considerar que éstos involucran relaciones entre representaciones de algún tipo que tendría el agente epistémico -llamadas "actitudes proposicionales" desde que Bertrand Russell introdujera el término- y estados de cosas externos a su conciencia. A esta tesis le es anexa otra: la función de representar estados de cosas exige un lenguaje representacional, cuya notación gramatical permita expresar únicamente aquellas partes oracionales que contribuyan a la verdad de dicha representación, y deje a un lado los elementos que obstaculicen o impidan dicho fin -metáforas, anáforas, modalizaciones, flexiones verbales subjuntivas, estilos, relaciones de significado, etc.-, dado que la verdad del acusativo proposicional de dichas actitudes proposicionales será una de las condiciones del conocimiento; lo que exige que la notación preserve exclusivamente los elementos oracionales que permitan expresar una proposición, esto es, que permita la identificación de los referentes y de los universos de discurso involucrados. En esa dirección un lenguaje que sirva para las representaciones cognitivas deberá ser un lenguaje que maximice la selección de dichas partes oracionales y permita eliminar las partes restantes. El ideal de ese lenguaje es lo que el filósofo y lógico W. O. Quine llamó "lenguaje canónico" o "notación canónica".

Quine introduce dicha noción ${ }^{21}$ como un lenguaje cuyo vocabulario estaría compuesto por variables individuales, constantes de predicado, conectivas extensionales, cuantificadores, identidad y signos de alcance, y cuyas reglas de formación serían las de la lógica clásica de orden uno; en coincidencia con ello, propone que toda la información científica sea formulada en dicha notación, ya que ella expondría de modo taxativo sus compromisos ontológicos y los contenidos cognitivos. El método para la obtención de una expresión en lenguaje canónico es la paráfrasis, que

21 Quine, W. O., El Sentido de la nueva lógica. Buenos Aires, Nueva Visión, 1971, passim. 
supone una serie de reescrituras de una oración que eliminen progresivamente las expresiones ambiguas o vagas, elementos retóricos, frases adverbiales, elementos indexicales, etc., para reemplazarlas por expresiones que únicamente posean significado literal despojando las construcciones oracionales de toda clase de dependencia contextual. El objetivo es llegar a una versión en lenguaje natural puramente extensional, desde la cual el pasaje hacia una fórmula de primer orden sería simple; a este castellano extensional se le pueden agregar los operadores algebraicos que fuera y así tenemos el lenguaje estándar de las ciencias fácticas. Esto deja fuera todo informe, reporte o testimonio que esté expresado en un vocabulario que incluya predicados intensionales como los de percepción o creencia, o que incluya los recursos dejados de lado por la notación gramatical canónica. Y dada esta preferencia por la verdad, la información que no se pueda expresar en notación canónica no satisfaría ese requisito de inteligibilidad -en el sentido de que al no haber un significado independiente de contexto sería difícil determinar de qué se está hablando- y por ende ella no tendría ningún rol cognitivo en el discurso científico.

El principio que subyace a esa mutua implicación entre teoría epistemológica y notación gramatical es simple: si la verdad es lo que importa, entonces la notación deberá resguardar la verdad. Pero este principio puede leerse de dos maneras: podemos ir desde el lenguaje hacia la teoría epistemológica, o podemos explorar la vía inversa: si la comprensión y el entendimiento conversacional es lo que importa, entonces la doctrina epistemológica debería integrar los actos de comprensión y constatación. $\mathrm{O}$, en terminología más afín a las presentaciones que hicieron los pirrónicos: si ciertas formas discursivas tienen un rol criteriológico, entonces ciertos roles cognitivos -considerando con ese rótulo a las formas de aceptación y estimación de lo-que-aparece que lleve a cabo un pirrónico en el mundo de la experiencia purificada- tendrían que ser tomados en cuenta en una doctrina sobre el tipo de saber que portase un pirrónico. Por ello la insistencia en la notación gramatical canónica tiene problemas, porque hay numerosos informes, reportes o testimonios que tienen roles criteriológicamente establecidos, y que no se pueden exponer con dicha 
notación, precisamente porque esto eliminaría los rasgos propios de dichos informes, reportes o testimonios ${ }^{22}$.

$\mathrm{Y}$ en ese sentido, ya en sus presentaciones clásicas, los pirrónicos señalaban que su lenguaje no era un lenguaje asertivo, sino que era lo que llamamos un lenguaje constatativo. Sexto Empírico dedicó una extensa sección de su tratado al análisis de las expresiones escépticas (HP, I 187209), y a hacer un deslinde minucioso entre el vocabulario asertivo y el vocabulario constatativo: así se diferencia de una posición nihilista al sostener que "aunque la expresión nada más presente los caracteres del asentimiento o la denegación [asentimiento del contrario], nosotros no la empleamos de ese modo, sino en un más amplio e impreciso sentido (...) proferimos la expresión nada más sin afirmar en absoluto que ella misma sea verdadera y segura, sino hablando también acerca de ella según lo que nos aparece" (HP. I, 191). El deslinde entre vocabulario asertivo y constatativo es sistemático. Sexto sostiene que la negación que aparece en sus declaraciones no es una negación al sostener que "la aseveración se dice en dos sentidos, general y especial; en sentido general indica afirmación y negación (...), en sentido especial indica sólo la afirmación" (HP, I, 192). Las expresiones negativas no aseverativas incluyen elementos pragmáticos inescapables y no admiten ninguna traducción en términos de la notación canónica, en la cual la única negación es la negación general o extensional, precisamente la que él rechaza. Y la notación canónica tampoco podrá acomodar la familia de operadores sintácticos que presenta Sexto (quizás, quizás no, es posible y es posible que no, puede ser que no, etc.), ya que éstos no se pueden expresar en una notación cuya función central es la representación de los elementos lexicales que contribuyan a la verdad independiente de contexto, lo que Sexto expone diciendo que "estas expresiones son indicadoras de la no aserción", ya que "no cuestionamos si las expresiones muestran las cosas en su naturaleza" (HP, I, 195).

22 Tómese el lector el trabajo de expresar en primer orden las construcciones con la estructura "Me parece que [verbo en potencial]", locuciones que muchas veces sirven para justificar o explicar una ejecución u omisión. 
El vocabulario no asertivo o constatativo es el material con el que los agentes doxásticos dan cuenta de pasado, presente y anhelos sin comprometerse con cómo sean las cosas en su naturaleza. Este dar cuenta se materializa en relatos que exponen lo que criteriológicamente escogemos hacer, y las significaciones que tienen aquellas acciones y resultados que logramos hacer, o lo que se nos enseña que se puede hacer, lo que hacemos entre todos o ponemos a debate, las trayectorias temporales, los modos de hacer cosas que sean más comunes y sus repeticiones, sus variaciones, sus modificaciones cuando aparecen cosas nuevas, la configuración de una tekbné y su inserción en diversos conglomerados de tékhnai. Así, mientras que la notación gramatical canónica impone una restricción a las inflexiones verbales en modo indicativo, la reducción de términos singulares a predicados y cuantificadores, y la oración simple como el paradigma de notación gramatical, el lenguaje constatativo acepta todos los modos verbales, los nombres propios y los indexicales y todas las modalidades adverbiales y el texto como paradigma de análisis.

\section{Conocimiento narrativo.}

Dijimos que la tesis que vincula lenguaje y teoría/doctrina del conocimiento puede leerse en dos direcciones: así, si las constataciones involucran una pluralidad de formas discursivas supra-oracionales y no extensionales, la doctrina del saber constatativo debería integrar estos rasgos. En esa dirección, podemos indagar los roles criteriológicos de las formulaciones constatativas en el ámbito de la experiencia purificada.

La teoría epistemológica estándar trató dos grandes tipos de conocimiento: el saber qué y el saber cómo. El primer tipo es aquel que acepta la notación gramatical de la extensionalidad y los portadores de verdad que ya tratamos; el segundo tipo de conocimiento es también llamado "conocimiento por reglas" e involucra las actividades seriadas y regulares -como aprender a manejar un automóvil o a cocinar porotos negros. Pero se han postulado otras formas de conocimiento, que pueden dar cuenta de 
dichos roles criteriológicos sin violar las declaraciones del pirrónico sobre su silencio acerca de lo que las cosas sean.

Entre las formas de conocimiento que se diferencia del saber qué y el saber cómo se halla el conocimiento narrativo; tal como sostiene Sarah Worth, hay una tercera especie de conocimiento:

argüiré (...) que esas narraciones bien construidas leídas, contadas y escuchadas (...) son beneficios epistemológicos [que sirven para] desarrollar y enriquecer la habilidad de razonamiento que surge del razonamiento narrativo [el que] nos ayuda a empatizar con otras personas, ser mejores ciudadanos, incrementar nuestra inteligencia y desarrollar un sentido coherente y sano de identidad personal ${ }^{23}$.

En el análisis de esta autora el conocimiento narrativo se manifiesta primariamente con la empatía y los vínculos comunitarios, pero esto no es una condición necesaria; la narratividad involucra una forma de presentar lo-que-aparece de cierta manera. Al caracterizar el conocimiento narrativo, Sara Worth sique la caracterización que hiciera Noël Carroll; de acuerdo con ella, una narración supone una estructura discursiva con los siguientes rasgos:

i. "Una narración] es aquella que se refiere al menos a uno, o posiblemente a más eventos y/o estados de cosas (...) una serie".

ii. "Para contar como conexión narrativa, un discurso que representa una serie de eventos tiene que tener un asunto unificador".

iii. "Los eventos y/o estados de cosas tienen que estar conectados, no pueden ser simplemente una lista de eventos y/o estados de cosas desconectados, [tienen que estar] ordenados en el tiempo en forma perspicua".

23 Worth, S., "Narrative Knowledge: Knowing through Storytelling", en http://web.mit.edu/comm-forum/mit4/papers/worth.pdf, pp. 2-4. 
iv. "Las narrativas no son cadenas de implicaciones causales aisladas, sino que los eventos iniciales de una secuencia de eventos sobredeterminan los ulteriores." 24

Noël Carroll intento elucidar el último rasgo en términos de una propuesta que hiciera J. L. Mackie: analizar la relación causal en términos de lo que llamó la clausula INUS ${ }^{25}$; esta cuestión, sin embargo, es completamente innecesaria para la caracterización del conocimiento narrativo. En efecto, la noción de sobredeterminación se puede entender en términos de una relación de dependencia temporal y de dirección, sin involucrar ninguna teoría de la causalidad. En ese sentido, los rasgos señalados caracterizan una trayectoria temporal en la que eventos y estados de cosas se vinculan por proximidad, y fragmentos de dicha trayectoria se vinculan con otros fragmentos en la lejanía, por la persistencia de ciertos rasgos en común. Eso sería la trama de la narración: una relación contingente, dependiente de contexto y corregible que involucra tanto a los agentes o cosas narradas como al narrador y sus interlocutores. $\mathrm{Y}$ en las constataciones regulares son las tramas las que tienen roles criteriológicos - por ejemplo, la escucha o atención precisa a lo que se dice, la interrogación desde el reconocimiento de huecos $\mathrm{u}$ omisiones, la discriminación afinada de la información latente o lateral, la provisión de conjeturas y pareceres que constaten los efectos y las formas de interpretación de lo-que-aparece a dicho agente que es el conocimiento narrativo.

Este conocimiento difiere tanto del conocimiento veritativo como del conocimiento operativo o por reglas o saber-cómo (know how). El conocimiento operativo es el tipo de conocimiento que un agente epistémico internaliza en sus sistemas motores y opera en modos

24 Carroll, N., Beyond Aesthetics: Pilosophical Essays, Nueva York, Cambridge University Press, 2001, pp. 120-121.

${ }^{25} \mathrm{La}$ sigla INUS es una contracción de la expresión inglesa "insufficient but nonredundant parts of a condition which is itself unnecessary but sufficient for the occurrence of the effect.", o "parte insuficiente y no redundante de una condición que es ella misma no necesaria pero suficiente para la ocurrencia de un efecto". 
previamente establecidos. Es un conocimiento fácilmente transferible y enseñable, a punto tal de que es el tipo de conocimiento involucrado en todo manual de procedimientos o protocolo de intervención en multitud de actividades y puede formularse por medio de lenguajes deónticos como sistemas de reglas de diferente orden, y por medio de árboles de decisión. Todos estos rasgos que básicamente garantizan su estabilidad y carácter público, son rasgos que el conocimiento narrativo no presenta.

Sin ánimo de ofrecer una doctrina completa del conocimiento narrativo podemos destacar lo que llamaríamos sus características básicas:

CN1. El conocimiento narrativo involucra las formas de hablar y escribir ordinarias de cada agente en su vida social tal como las adquiere y sin ninguna especialización lexical o gramatical.

CN2. El conocimiento narrativo supone que el agente pueda tener informes y relatos inconsistentes y que pueda efectuar nuevos relatos inteligibles a partir de aquellos.

CN3. El conocimiento narrativo parece tener una dependencia de contexto de la que no se puedan separar los informes y relatos que se provean o que se produzcan.

CN4. Los informes y relatos que se provean o produzcan podrán tener un cierto grado de vaguedad intrínseca.

CN5. El conocimiento narrativo supone al conocimiento procedimental (know how) como un elemento en la provisión o producción de informes y relatos.

CN6. El conocimiento narrativo supone que la información cenestésica tiene ciertos roles en la instrucción y adiestramiento perceptual.

CN7. El conocimiento narrativo supone que en algunos casos los conceptos básicos involucrados en nuestros informes y relatos 
sobre lo-que-aparece en la experiencia purificada tienen una dimensión vincular irrenunciable de segunda persona ${ }^{26}$.

\section{Medicina y conocimiento narrativo.}

Una vez presentado el primer término de la relación, debemos abordar el segundo. Ahora bien, ¿cómo se puede caracterizar la noción de escuela médica dada la enorme complejidad y diversidad de las ciencias de la salud actuales? Esto supone examinar brevemente la constitución de dichos ámbitos.

Es difícil caracterizar a las ciencias de la salud con la categoría escuela médica incluso si nos restringimos a las actividades que se llaman a sí mismas medicina, término que aparece en sintagmas como Medicina Ayurvédica, Medicina Ortomolecular, Medicina Naturista, Medicina Oficial, Medicina Psicosomática, etc. Si sólo se considerara cómo se llaman a sí mismas, cualquiera de esas actividades podría llamarse escuela

${ }^{26}$ Este punto ha sido tratado en la filosofia práctica; Stephen Darwall señala al respecto: "Estas nociones -autoridad de la segunda persona, reclamo o demanda válida, razón de segunda persona, y responsabilidad para...- constituyen un círculo interdefinible, cada una de ellas implica a las restantes. Sin embargo, reconozco que no hay forma de romper el círculo desde dentro. Las proposiciones formuladas con conceptos descriptivos y normativos que no sean implícitamente segundo-personales, no pueden justificar en forma adecuada las proposiciones formuladas en el interior de dicho círculo (...) la autoridad práctica de la segunda persona irreductible difiere de y no puede ser reducida a la autoridad de otra clase. Considérese por ejemplo la autoridad epistémica (...) Incluso si la manera en que respetamos la autoridad epistémica es frecuentemente de segunda persona -dando crédito a los reclamos epistémicos de alguien en discusiones acerca de que creer- la autoridad epistémica no es en sí misma de segunda persona, es de tercera persona. Ella depende fundamentalmente de las relaciones que tiene la persona con los hechos y la evidencia que haya, y no de sus relaciones con otros cognoscentes racionales" (Darwall, S., The Second-Person Standpoint. Morality, Respect, and Accountability, Cambridge (Mass.), Harvard University Press, 2006, p. 12). 
médica, pero ello exigiría que todas ellas fueran homologables: en efecto, si algo es una escuela médica, debería presentar cierta estructura común con otras que lo sean. Pero esto no ocurre, ya que hay una diferencia crucial entre la llamada Medicina Oficial (en adelante MO, como aquella disciplina enseñada en las Facultades de Medicina y regida por leyes de ejercicio profesional y colegios profesionales que se reconocen entre sí en el mundo) y las que se agrupan en bajo la denominación Medicinas Alternativas y Complementarias (MAC). Sin entrar en ninguna consideración acerca de su estatuto gnoseológico o su carácter de disciplinas que emplean verdades o falsedades, la diferencia no radica tanto en el propio contenido médico, sino en las teorías fundamentales que comprometen. En sentido estricto, la diferencia entre $\mathrm{MO}$ y MAC no es en rigor una diferencia médica sino una diferencia física, química o biológica, y en ese caso no habría que hablar de escuela médica sino de escuela física, química o biológica; por ello -para que tenga sentido la expresión escuela médica- nos limitamos a considerar aquellas formas terapéuticas que acepten las mismas teorías fundamentales físicas, químicas y biológicas sin considerar su estatuto gnoseológico ${ }^{27}$.

Esto exige considerar mínimamente el origen de MO: esta disciplina nació en 1878, en la ciudad de Leipzig cuando Paul Ehrlich (Silesia, 1854-1915, Premio Nobel de Fisiología y Medicina en 1908) defendió su tesis doctoral Beiträge zur Theorie und Praxis der histologischen

${ }^{27}$ En numerosas MAC hay cambios radicales en la terminología empleada: en las escuelas de Reiki el uso de la palabra energía difieren completamente del uso que se hace en la dinámica clásica o relativista; en la medicina homeopática, por su parte, los conceptos de solución y de enlace químico varían completamente del uso que hace de ellos la química que se funda en la teoría atómica de Dalton y Avogadro. Por ello hay que decir que el conflicto entre reiki (una técnica de imposición de manos) y la dinámica clásica o relativista y el conflicto entre la medicina oficial y la medicina homeopática NO SON conflictos médicos sino físicos o químicos. En el caso que nos ocupa, el escéptico pirrónico podría justificar su elección de una escuela médica y no de otras diciendo: "Voy a limitarme a señalar mis diferencias y similitudes con todos aquellos que comparten un lenguaje común -el lenguaje de las teorías fundamentales- sin abrir juicio sobre la pertinencia o no de dicho lenguaje." 
Färbung (Contribución a la Teoría y Práctica del Tintado Histológico) que significó un cambio radical con la medicina precedente: la incorporación sistemática de la industria químico-farmacéutica como actor central del proceso terapéutico al producir medicamentos específicos. A partir de su formación química, Paul Ehrlich pudo emplear tinciones - como el azul de metileno y el indofenol- para el estudio de las toxinas y sus efectos en los receptores de las membranas celulares; su programa está contenido en un párrafo de su Conferencia Nobel:

en este momento, ha llegado la hora de penetrar en el interior del quimismo más sutil de la vida celular, y cambiar el concepto de la célula como una unidad en el concepto de un gran número de partes individuales con funciones específicas. Pues lo que sucede en la célula es básicamente de naturaleza química y dado que las estructuras químicas están más allá de los límites de la percepción visual, debemos encontrar otros métodos para investigar esto. Este enfoque no sólo es de gran importancia para una comprensión real del proceso de la vida, sino que es la base para un uso verdaderamente racional de sustancias medicinales. El primer avance en este campo complicado, fue, como sucede frecuentemente, azaroso. Después del notable descubrimiento de las antitoxinas por Bebring, me aboque a la tarea de penetrar más profundamente en la naturaleza misteriosa de ese proceso, y luego de un largo trabajo, tuve éxito en encontrar sus claves ${ }^{28}$.

La frase central puede considerarse como el axioma fundamental de la medicina realmente existente al determinar la alianza entre práctica terapéutica y tecnología fármaco-química dando lugar a lo que ha sido llamado Modelo Biomédico o Modelo Médico Hegemónico. Dicho de otro modo: la revolución ehrlichiana fija una relación efectiva entre medicina y ciencias químico-biológicas en cuyo marco debemos localizar aquello que llamaremos escuela médica, para que la disidencia sea exclusivamente una disidencia médica y no sobre alguna otra disciplina más básica. En ese marco es posible reconocer al menos dos escuelas médicas

${ }^{28}$ Ehrlich, P., "Conferencia Nobel 1908", en Nobel Prizes, Physiology or Medicine 1901-1920, Amsterdam, Elsevier Publishing Company, 1967, pp. 304-5. 
actuales: la Medicina Basada en Evidencia (MBE) y la Medicina Basada en Narraciones (MBN).

Tanto MBE como MBN son casos de $\mathrm{MO}$ ya que ambas aceptan las mismas teorías fundamentales; su disidencia se da exclusivamente en el orden del conocimiento diagnóstico, o sea en la consideración de los insumos que deba emplear -para formular un juicio clínico- un agente terapéutico en situación de encuentro terapéutico con un sujeto que padece. De acuerdo con ambas escuelas médicas habría dos tipos de conocimiento diagnóstico: el Conocimiento Diagnóstico Discursivo -que corresponde a MBE- y el Conocimiento Diagnóstico Narrativo -que corresponde a MBN_29.

Las tareas fundamentales del conocimiento diagnóstico discursivo son la clasificación -que en caso de las ciencias de la salud supone la subsunción del caso en una entidad nosográfica definida por algunas de las nosografías específicas (DSM IV R, ICD-10, ICD-O-3, SNoMed-CT, etc.)-, y la medición - por medio de sistemas de análisis bioquímicos y anatómico-patológicos estandarizados- lo que permite "asegurar la precisión y certeza del diagnóstico"30, que será entendido como "la correspondencia entre lo que se encuentra y el estado verdadero de la entidad o fenómeno que es descripto"31. Los síntomas son indicadores subjetivos para la búsqueda de signos clínicos, que serán luego medidos y subsumidos para la formulación de un diagnóstico registral de modo que "signos, y en menor medida los síntomas, juegan un rol epistemológico vital, no solo en el tratamiento sino para establecer el conocimiento diagnóstico"32. La información que provee el sujeto que padece será considerara el punto terminal subjetivo de una cadena etiológica que comienza -conceptualmente- con el estado nosográfico imputado; por

${ }^{29}$ Marcum, J., An introductory philosopby of medicine: bumanizing modern medicine, Nueva York, Springer, 2008.

${ }^{30}$ Ibíd., p. 154.

31 Ibíd., p. 157.

32 Ibíd., p. 155. 
ello la información verbal que provea el sujeto que padece será analizada desde la entidad nosográfica.

Para ello se aplican las técnicas estadísticas de análisis y la nomenclatura de almacenamiento en bases de datos clínicos que operan como insumo para que el agente terapéutico (i) atribuya una entidad nosográfica a un paciente y determine la posible curva de resultados que tendrá la intervención terapéutica, y (ii) aplique el protocolo de intervención clínica estandarizado para dicha entidad nosográfica; en ese sentido MBE supone el modelo estándar de conocimiento asertivo y de metodología científica estadístico-inductiva; el juicio clínico es la traducción del síndrome en una secuencia de datos registrales ${ }^{33}$ y su subsunción en el conjunto de generalizaciones taxonómicas y en la red teórica correspondiente.

En la medida que los estados nosográficos se expresan por medio de datos registrales, esto permite la incorporación masiva de tecnología biomédica de tratamiento: en efecto los sistemas mecánicos necesitan ser ajustados a valores de rendimiento que correspondan con estados objetivos de cada entidad nosográfica. Al mismo tiempo, la intervención terapéutica se enriquece con tecnologías biomédicas de observación, lo que permite ajustes en la farmacología. En ambos casos la condición necesaria del funcionamiento de la tecnología biomédica será la existencia de nosografías registrales afinadas.

Ahora bien, sin poner en discusión ni la nosografía ni las tecnologías biomédicas, la raíz del conflicto entre MBE y MBN surge de la siguiente cuestión: ¿la determinación del juicio clínico -la evaluación diagnóstica y terapéutica de un sujeto específico- para encarar una intervención terapéutica con cualquier grado de complejidad técnica, que

${ }^{33} \mathrm{El}$ concepto de dato registral es fundamental en las ciencias; en el caso de las ciencias de la salud los datos registrables involucran instrumentos -termómetros, tensiómetros, microscopios, reactivos, filtros, etc. - y escalas -número de glóbulos rojos, presión distal, tiempo de reacción- que contienen valores de normalidad o patologicidad. Por ello, para el agente terapéutico el índice de ácido úrico en sangre sólo será un dato tiene un valor normal o no. 
modere o elimine dicho padecimiento es posible con la información que proveen los procedimientos registrales de análisis anatómico-patológicos o será necesaria otro tipo de información para lograr que la intervención terapéutica sea eficaz? Esta pregunta señala que el debate entre MBE y MBN no involucra ni la distinción entre el polo objetivo y del polo subjetivo de la relación de conocimiento, ni una distinción entre las ciencias de lo singular y las ciencias de lo general -si bien estas cuestiones se cruzan en forma casi directa con la anterior- sino que dicho debate se da exclusivamente en términos de los tipos de información que se deban emplear en el juicio clínico.

Los autores que sostienen $\mathrm{MBN}$ responden negativamente a la primera parte de la pregunta anterior y ello porque los proponentes de la MBN sostienen la necesidad de un instrumento específico para configurar un juicio clínico que guíe una intervención efectiva: la Trama. Como señala James Marcum, "la estructura que provee la Trama de la historia a la narración, sirve como punto focal sobre el que la secuencia temporal de eventos converge y se organiza. La Trama, antes que lógica o causación, funciona como conectora de los eventos. No sólo estructura la dimensión temporal de los eventos, sino también sus dimensiones no-temporales." 34 . El autor cita a Sarah Worth, quien da un ejemplo preciso:

El razonamiento discursivo se ejemplifica por el siguiente argumento lógico:

F: "Sócrates es hombre todos los hombres son mortales, Sócrates es mortal". Aunque puede haber historias sobre la mortalidad de Sócrates (como de hecho las hay) $\mathrm{F}$ no tiene una estructura narrativa real sobre Sócrates, la que sería más o menos así:

G: "Hubo un hombre llamado Sócrates, que a causa de sus sugerencias que la gente necesitaba cuestionar los fundamentos del conocimiento de modos que jamás se habían tratado antes, fue acusado de hereje, juzgado y condenado a muerte por medio de la cicuta".

Hay una línea de argumentación identificable en $F$ de la que carece $G$. Sin embargo, en $G$ hay una estructura narrativa que nos permite seguir los

${ }^{34}$ Marcum, J., An introductory philosophy of medicine: bumanizing modern medicine, pp. $161-2$. 
eventos en la narrativa y comprender como la conclusión -que Sócrates fue conminado a morir- se sigue lógicamente, e incluso nos permite deducir lo que está antes. En el segundo ejemplo no hay conclusión lógica, que se pueda probar de lo que aparece antes, pero hay una estructura narrativa identificable que se puede señalar ${ }^{35}$.

Nuestro conocimiento asertivo sobre Sócrates puede afirmar que Sócrates murió porque Sócrates era una de estas entidades -un bomo sapiens- que sufre cesación vital completa; pero ello no explica por qué murió Sócrates más que por qué no aceptó las ofertas de sus discípulos para escapar al castigo; solo la narración $G$ permite asomase a esa cuestión. $\mathrm{E}$ incluso $\mathrm{G}$ parece incompleta: sólo cuando exponemos la enseñanza socrática sobre la virtud cívica podría responderse a la pregunta de por qué murió Sócrates.

El contraste entre la explicación discursiva y la explicación narrativa, así como el tipo de información que cada tipo de explicación provee es total. Rita Charon -una de las pioneras de dicho movimientoavanza en esta caracterización del $\mathrm{MBN}$ : "Uso el término medicina narrativa para designar las prácticas médicas con habilidades narrativas como reconocer, interpretar y ser motivado por las historias de la enfermedad"36.

El agente terapéutico que opera desde MBN tiene ciertos objetivos básicos: "Tuve que seguir el hilo narrativo del paciente, identificar las metáforas o imágenes empleadas en su relato, tolerar la ambigüedad y la incertidumbre mientras el relato se desarrollaba identificar el subtexto implícito, y escuchar un relato a la luz de otros contados por el narrador" 37 . Estas destrezas o capacidades se pueden adquirir o mejorar en el ejercicio, de modo que los agentes terapéuticos deberían ser entrenados en "la habilidad para percibir el sufrimiento, para brindar rigor interpretativo de aquello que se percibe, para manejar las

${ }^{35}$ Worth, S., "Narrative Knowledge: Knowing through Storytelling", p. 8.

${ }^{36}$ Charon, Rita, Narrative medicine: honoring the stories of illness. Nueva York, Oxford University Press, 2006, pp. 3-4.

37 Ibíd., p. 8. 
inevitables oscilaciones entre la identificación y el desapego, para ver los eventos de la enfermedad desde múltiples puntos de vistas, para vislumbrar las ramificaciones de la enfermedad" 38 .

En cada caso el agente terapéutico porta un tipo de saber que difiere del conocimiento teórico fundado en evidencia, y a ese tipo de saber Rita Charon lo llama conocimiento narrativo:

A diferencia del conocimiento científico o epidemiológico, que trata de descubrir resultados sobre el mundo natural que sean universalmente verdaderos, o que aparezcan verdaderos para cualquier observador, el conocimiento narrativo permite que un individuo pueda comprender eventos particulares que aquejan a otro individuo no como instancias de algo que sea particular sino como una situación singular y significativa ${ }^{39}$.

De acuerdo con la descripción que hacen Rita Charon y James Marcum, si bien el agente terapéutico puede tener conocimiento teórico fundado en leyes universales y generalizaciones empíricas, sobre las enfermedades, el conocimiento que guíe su intervención terapéutica será local, idiosincrático y receptivo, y motivará la acción. Esto es, yo, en cuanto agente terapéutico, para ser motivado para actuar por la serie de objetivos básicos mencionada anteriormente, "también tendré que darme cuenta de mi propia respuesta a lo que escucho, permitiéndome que sea motivado para actuar en beneficio del paciente" 40 .

En este punto la autora menciona la especificidad de MBN respecto de MBE: la posibilidad de obtener información que no pueda tratarse con las herramientas metodológicas de MBE ya que los sujetos padecen estados que son "rebeldes y elusivos (...) porque el dolor, el sufrimiento, la preocupación, la angustia y la sensación de que algo no está bien, son condiciones muy difíciles, sino imposibles, de poner en palabras" 41 .

\footnotetext{
38 Ibíd.

${ }^{39}$ Ibíd., p. 9.

${ }^{40}$ Ibíd., pp. 8, 4.

${ }^{41}$ Ibíd., p. 4.
} 
Esta interacción entre un agente terapéutico y un sujeto que padece, en la que este último provee información tácita que se expresa por medio de informes o relatos que usan recursos verbales retóricos o erísticos que tienen textura abierta, que presentan conflictos de interpretación, no solo exigen del agente terapéutico una destreza técnica en el manejo de la nosografía, sino una tarea hermenéutica de intérprete en la imputación y ajuste de una trama. Será esa información imprecisa, vaga y local, la que opere como dirección o guía de cada acto del agente terapéutico cuando éste se sitúe en posición de escucha de la palabra del sujeto que padece y no de inferencia subsumidora desde taxones o proposiciones generales.

\section{Escepticismo pirrónico y MBN.}

El pirrónico puede tomar nota de lo sucede en la medicina y afirmar: "Muy bien, convenimos que las situaciones de isostheneia son irresolubles, y que no podemos salir de ellas sin angustia, por lo que suspendemos el juicio y súbitamente nos encontramos en una experiencia purificada de creencias asertivas". A esto, por su parte, podría objetársele: "Bueno, pero Ud. me dice que debo aceptar un tipo de conocimiento que se funda en los informes y relatos que hace la gente, pero esos informes y relatos son completamente arbitrarios, fantasiosos, autocomplacientes, entonces Ud. me dice que debo aceptar una fuente de información que parece ser tan precaria como las creencias asertivas de las comunidades epistémicas que se dicen especializadas y autorizadas -las disciplinas académicas- lo que me precipitaría en una situación similar.".

Esta objeción es atendible, pues la gente común farfulla sobre las cosas con una suficiencia que no se diferencia de la de los dogmáticos más petulantes. Pero es fundamentalmente incorrecta. En primer lugar el par conocimiento discursivo o lógicamente encadenado y fundado en evidencia/ / conocimiento narrativo o basado en narraciones se diferencia por los tipos de información que se brinda en ellos y no por la afirmación de la realidad o irrealidad de algo. En ese sentido constatar lo-que-aparece no exige determinar el carácter real o ficcional de aquello que es constatado: la cuestión que 
importa es que la información narrativa no sea episódica y aislada sino que exhiba plexos de eventos o estados de cosas que conformen aquello que Porchat Pereira llamó enriquecimiento y perfeccionamiento de la imagen común del mundo, de ese mundo que aparece en modo insistente como pasible de una descripción consensual e irrelevante. $\mathrm{Y}$ podemos considerar que ese mundo es enriquecido y perfeccionado por un entramado, en el sentido de ofrecer tramas ajustadas entre sí y entre sus fases temporales, revisadas en cada constatación, sin que ninguna de ellas sea una representación cognitiva verdadera.

Dada esta estructura mutable de lo-que-aparece, se impone una segunda consideración. Este mundo enriquecido y perfeccionado que aparece se presenta como un mundo comunal -en las tradiciones y en las técnicas que él mismo reconoce-, es el ámbito donde transcurre la propia temporalidad de cada agente. $\mathrm{Y}$ esta temporalidad es la piedra de toque de la no arbitrariedad y relevancia mutua de las narraciones personales o compartidas.

No es el carácter real o fabuloso de un informe o relato lo que lo haga inútil o descartable, o que lo haga interesante y útil, es su carácter temporal. Esa temporalidad es el núcleo de las tramas que organizan los informes y relatos que provee el conocimiento narrativo, y se manifiesta y compone imaginativamente sin ninguna necesidad de justificación epistémica.

Ello supone que las tramas exponen ciertos conglomerados complejos, persistentes, de tekhnai y que por ello tienen un rol criteriológico en la consideración de la totalidad de lo-que-aparece. $\mathrm{Y}$ en ese sentido el conocimiento narrativo terapéutico es ejemplar. Podemos retomar la caracterización que ofreció Rita Charon: el encuentro terapéutico es el encuentro de un agente terapéutico provisto de saberes procedimentales y un sujeto que padece, para intervenir en el padecimiento y lograr un estado antagónico; el agente terapéutico debe saber qué hacer, y al mismo tiempo debe modular lo que sabe al caso, y ello supone recabar toda la información que sea relevante sobre el padecimiento. $\mathrm{Y}$ parte de esa información no será del tipo de la que se obtiene con cuestionarios protocolizados y preguntas $\mathrm{Si} / \mathrm{No}$, sino que es 
información sobre eventos que muchas veces no son recordados, o que lo son en modos incompletos, o que son investidos de valoraciones o que sólo aparecen cuando la interrogación dirigida lleva el foco de atención a esas ausencias del relato, aquello que duele ahora y toma toda tu atención no es siquiera parecido al conjunto de signos que puedo observar inflamación, enrojecimiento, deformación, etc.- y lo que me interesa es tu dolor, que es lo que el agente terapéutico tiene que revertir. Y ello no solo supone atender a que tienes dolor, sino entender este dolor en tu experiencia vital, atender a los efectos incapacitantes de dicho dolor en tu vida en cada día. Por ello, el agente terapéutico no es un agente "tironeado" por los hechos, sino que su comportamiento tanto está guiado por saberes técnicos y justificados - de los que dará cuenta el dogmático si puede- como por tramas montadas sobre los relatos del sujeto que padece, que guían criteriológicamente la entrevista y la búsqueda de todas esas formas de información que exceden a los datos clínicos; por ello es un comportamiento proactivo, porque el agente terapéutico sabe que siempre hay un excedente a todo síndrome, aquello que Rita Charon señalara como difícil sino imposible de poner en palabras. Y no hay ningún camino inferencial que lleve al agente terapéutico a conocer tu dolor o padecimiento ${ }^{42}$.

Esto supone que el estudio y la atención a MBN es una tarea que puede emprender un pirrónico, en la media que en $\mathrm{MBN}$ puede encontrar en forma ejemplar los roles criteriológicos de las tramas como herramientas que permiten vivir en un mundo común y purificado.

Recibido: 07/2013. Aceptado: 11/2013

42 En esa dirección pueden verse las propuestas de emplear instrumentos psicodinámicos en la interacción entre médicos y pacientes tal como la propusiera Michael Balint luego de sus investigaciones en el Tavistock Institute of Human Relations en Gran Bretaña. Cfr. Balint, M., The Doctor, His Patient and the Illness. Londres, Churchill Livingstone, 1957. 